\title{
A theory guided nursing intervention for management of hypertension among adults at rural area
}

\author{
Amal Attia Hussein, Entsar Abd Elaleem Abd El Salam * Asmaa El sayed Farid Amr \\ Community Health Nursing, Faculty of Nursing, Menoufia University, Menoufia, Egypt
}

Received: March 28, 2016

DOI: $10.5430 /$ jnep.v7n1p66
Accepted: July 11, 2016

URL: http://dx.doi.org/10.5430/jnep.v7n1p66

\begin{abstract}
Background and objective: Hypertension is one of the most important preventable causes of premature morbidity and mortality in the world. Many people with hypertension both in developing and developed countries have no adequate control of their blood pressure. Lifestyle modification and adherence to antihypertensive drugs play an important role in controlling hypertension and in preventing its long-term complications. Aim: This study was conducted to assess the effect of application of Pender's Health Promotion Model on management of hypertension among adults in rural area.

Methods: Quasi-experimental design was utilized. The sample of this study was a purposive sample of 150 adults with hypertension. Setting: This study was conducted at El-Shahid Fekry village and Abu-Mashhour village at Menoufia Governorate. Tools used were (1) An interview questionnaire containing three parts of the model: a) Individual characteristics and experience, b) behavior-specific cognitions and affect, and c) behavioral outcomes. (2) Physical measurement included anthropometric measurements.

Results: The highest percentages of hypertension were among age group between 50-60 years (44.7\%), female (69.3\%), and illiterate $(34.7 \%)$. There was statistical significant improvement among the study group than the control group at the posttest of the systolic and diastolic blood pressure in relation to the components of Pender's health promotion model $(p=.0001)$.

Conclusions and recommendations: Application of Pender's Health Promotion Model was effective in management of hypertension. Also, nursing educational intervention was successful in improving knowledge, lifestyle behaviors and blood pressure measurement among adults in the study group than the control group. Recommendations: Health education programs to increase awareness of adults about risk factors of hypertension and the disease process is essential to empower and motivate them to adopt healthy lifestyle and adhere to medication to manage the disease and prevent complication.
\end{abstract}

Key Words: Hypertension, Pander's health promotion model, Lifestyle modification

\section{INTRODUCTION}

Hypertension (HTN) is a significant public health concern all over the world, in term of morbidity, mortality, and economic burden especially among adults. It is the leading and most important modifiable risk factor for heart diseases, stroke, renal diseases and retinopathy. ${ }^{[1]} \mathrm{HTN}$ is a persistent elevation of the systolic blood pressure (SBP) at a level of $140 \mathrm{mmHg}$ or higher and diastolic blood pressure (DBP) at a level of 90 $\mathrm{mmHg}$ or higher based on the mean of two or more seated blood pressure readings on 2 or more consecutive visits to the clinic. ${ }^{[2]}$

Data from the National Health and Nutrition Examination Survey ${ }^{[3]}$ indicated that the age-adjusted prevalence of hypertension was $29.1 \%$ among United State (US) adults aged 18

\footnotetext{
*Correspondence: Entsar Abd Elaleem Abd El Salam; Email: entsargodia@ gmail.com; Address: Community Health Nursing, Faculty of Nursing, Menoufia University, Menoufia, Egypt.
} 
years and over. The morbidity from hypertension in US was $31.9 \%$ in adults aged 20 years and over. ${ }^{[4]}$ In Arab countries, the overall estimated prevalence of hypertension was $29.5 \%$ occurring more frequently in Arab women than men. ${ }^{[5]}$ In Egypt, the most recent study about the Egypt STEP wise survey for cardiovascular disease risk factors conducted by the Egyptian Ministry of Health and Population in collaboration with the World Health Organization (WHO) office in the years 2011-2012 reported that the prevalence of hypertension in Egypt was $39.7 \%$ in persons aged 15-65 years with $38.7 \%$ for men and $40.8 \%$ for women. In $60 \%$ of patients, hypertension is complicated by the presence of other cardiovascular risk factors, this adds to increased morbidity and mortality. ${ }^{[6]}$

Hypertension is known as the "silent killer" because it usually occurs without symptoms. Hypertension takes a long time before diagnosed thereby causing major health problems as stroke and other cardiovascular diseases. ${ }^{[7]}$ Obesity, unhealthy diet, diabetes mellitus, excessive alcohol intake, physical inactivity and smoking are considered risk factors associated with hypertension. ${ }^{[8]}$

Treatment of hypertension is not only aimed at lowering blood pressure, but also concerned with how to reduce risk factors associated with developing complications. Non-pharmacologic treatment focuses on self-management, lifestyle modification and promoting appropriate healthpromoting behaviors. Lifestyle modification is the treatment recommended by physicians and includes diet control, body weight control, physical activity and stress management, in the other hand, pharmacological treatment is the cornerstone for disease treatment to reduce the high blood pressure and prevents complications such as cardiovascular and renal morbidity and mortality. ${ }^{[9,10]}$

In Egypt, management of hypertension is not easy as a result of treatment cost which is a common cause of treatment interruption, inadequate physician training and inefficient primary health care system. ${ }^{[11]}$ Measures to improve blood pressure control in Egypt include availability of health care system and better physician's and patient education regarding hypertension disease, treatment and control. ${ }^{[12]}$

Pender's Health Promotion Model is important to be used because people can take the initiative to take care of their own health. It is important to the patient understand that hypertension is a chronic disease, because of their lack of knowledge and unawareness of the signs and symptoms of disease, they visit a health facility complaining about other health problems and are then diagnosed with hypertension. Engagement in health promoting behavior to one's benefit is important to ensure good health. So, this model recommended that health care provider should provide intensive education to people regarding their lifestyle habits to prevent complication of the disease. ${ }^{[13]}$

The nurse has an important role in management of hypertension, she is not only identifying and treating patients with hypertension but also should promote a healthy lifestyle and preventive strategies to decrease the prevalence of hypertension among adults population. ${ }^{[14]}$ The nurse should encourage the patients to lower their blood pressure (BP) by maintaining health diet, Ideal body weight, reducing sodium intake, increasing physical activity and managing stress. ${ }^{[15]}$ This goal can be achieved through supporting and teaching the patients to adhere to treatment regimen, importance of staying on medications even though they do not feel any difference, or perhaps feel worse because of side effects, and by implementing necessary lifestyle changes. ${ }^{[16]}$

\subsection{Significance of the study}

According to the latest WHO data published in April 2011, hypertension deaths in Egypt reached 14,300 (3.94\%) of total deaths. The age adjusted death rate is 31.57 per 100,000 of population which ranks Egypt as 70th in the world. ${ }^{[2]}$ The high mortality rates from hypertension may be due to the health systems in this country, where treatment of chronic diseases is inadequate due to lack of specialized health personnel, inadequate facilities, lack of intensive care, lack of some medicines, and lack of awareness among patients about hypertension. ${ }^{[17]}$ So, Pender's Health Promotion Model (HPM) was used in this study for two reasons. The first is that the HPM focuses on the relationship between individual's characteristics and experiences, behavior specific cognitions, and behavioral outcomes. The second is that the HPM assumes that people take an active role to maintain healthy behaviors and change their environment context to support these behaviors.

\subsection{Aim of the study}

This study aims to assess the effect of application of the Pender's Health Promotion Model on management of hypertension among adults in rural area.

\subsection{Research hypothesis}

(1) Hypertensive adults, who will receive the intervention strategy, will have better lifestyle behaviors than hypertensive adults who will not receive the intervention strategy.

(2) Hypertensive adults, who will have better lifestyle behaviors, will have controlled blood pressure than hypertensive adults who will not have better lifestyle behaviors. 


\section{SUBJECTS AND METHODS}

\subsection{Research design}

Quasi-experimental design was used to achieve the aim of this study.

\subsection{Research settings}

A multistage random technique was used to select the setting according to the following system:

(1) The first stage was random selection of one district from nine districts in Menoufia Governorate. The selected district was Birket Elsaba.

(2) The second stage was random selection of two villages from Birket Elsaba district. The selected villages were Abu-Mashhour and Elshahid Fekry. Each village has family health center from which the sample was taken.

\subsection{Subjects}

Purposive samples of 150 adults with hypertension who were registered in the chronic disease sheets as hypertensive and were attending the family health centers of the two villages for follow up were recruited. They were divided randomly by tossing a coin into two groups (study group from AbuMashhour and control group from Elshahid Fekry). The sample was selected according to the following inclusion criteria:

(1) Adult aged 18-64 years.

(2) Diagnosed with hypertension combined with or without other disease.

\subsection{Tools of data collection}

Data were collected through the following tool which included:

- Interview questionnaire

- Physical measurement

\section{1) Interview questionnaire}

An interviewing questionnaire was constructed and developed by Nola Pender, $2002^{[18]}$ and modified by the researcher for culture orientation of the questions to collect the necessary data from adults with hypertension.

The modified Pender's HPM had three main components as follows:

- Part I: The individual characteristics and experiences,

- Part II: Behavior-specific cognitions and affect, and

- Part III: Behavioral outcomes.

Part I: Individual characteristics and experience which included:

68
- A-Personal factors that include:

- Demographic data, Medical history, Family medical history, Specific question for women, Knowledge about hypertension. It included 6 closedended questions numbered (15-20) in the tool. These questions developed by Janet (2011) ${ }^{[19]}$ and modified by the researcher: Each correct answer was given 1 point based on predetermined key answer according to the literature, while incorrect answer was given zero. The total score ranged between 0-6 points. ${ }^{[19]}$ The scoring System was categorized as follow:

$*$ Poor knowledge $<3$ points.

* Good knowledge $\geq 3$ points.

- B-Prior related behaviors which included:

- Nutritional habits, Health habits, Rest and daily activity, Stress and anxiety.

- Hill-bone blood pressure medication compliance scale: The Hill-Bone-Scale developed by Kim, Hill, Bone, \& Levine, 2000. ${ }^{[20]}$ It was modified by the researcher. It was used to assess patient behaviors for two behavioral domains of hypertension treatment which comprises 10 questions that are summed up to subscales: medication taking (eight items) and appointment keeping (two items). Each item could be answered on a 3point- Likert scale. The grading of the scale is as follows: None of the time $=3$, some of the time $=2$, All of the time $=1$. Total score of Hill-bone blood pressure medication compliance scale is 30 degree which graded as low compliance (< $50 \%)$ to $10-19$ degree, moderate compliance (from $50 \%$ to $<75 \%$ ) to $20-24$ degree and high compliance ( $\geq 75 \%-100 \%)$ to $25-30$ degree.

Part II: Behavior-specific cognition and affects developed by Angelina (2012) ${ }^{[21]}$ and modified by the researcher which include: Perceived benefits, Perceived barriers, Perceived self- efficacy, Interpersonal influences, Situational influences.

Part III: Health promoting behavior (Behavior outcome): developed by Glenn (2010) ${ }^{[22]}$ and modified by the researcher. This part included five health promoting behaviors: Nutritional adherence and weight reduction, adherence to physical activity, smoking cessation, Stress management, and medication adherence.

\section{2) Physical measurements}

Physical measurements which included:

- Anthropometric measurements: For each hypertensive adult weight and height were measured and recorded to calculate Body Mass Index (BMI).

ISSN 1925-4040 E-ISSN 1925-4059 
- Weight: Body weight was measured in kilogram (kg) using weight scale.

- Height: Height was measured in centimeter $(\mathrm{cm})$ by using measuring tape.

- Blood pressure was measured in millimeter of mercury (mmHg) using blood pressure instrument.

\section{MethodS}

\subsection{Review of literature}

Review of the past and current literatures that cover the various aspects of the problem was done using books, periodical articles, magazines and network about studies related to application of Pander's HPM in management of hypertension among adults.

\subsection{Administrative approval}

An approval of the ethical committee was obtained to carry out the current study. Official letters were taken from the dean of Faculty of Nursing in Menoufia University to the director of each Family Health Center to obtain agreement for data collection and a permission to carry out the study after explanation of the purpose of the study.

\subsection{Ethical considerations and human rights}

Protection of human rights was emphasized on subjects that the participation in the study was voluntary. Anonymity and confidentiality of responses was respected. Adults with hypertension were given an opportunity to refuse to participate in the study and they were notified that they could withdraw at any stage of the research. Adults with hypertension who agree to participate in the study included and their oral consent was obtained.

\subsection{Validity}

The tool was constructed and developed by Nola Pender, 2002 and modified by the researcher after review of the related literature and tested for its content validity by four experts (three assistant professor of Community Health Nursing, and one lecturer in Community Health Nursing) and one expert of Psychiatric health nursing (lecturer in Psychiatric health nursing). The needed modifications were done.

\subsection{Reliability}

Reliability of the tool was applied by the researcher for testing the internal consistency of the tool, using Test retest reliability, this method was done by administration of the same tool to the same subjects under similar conditions on one or more occasions. Answers from repeated testing were compared. The correlation between scores on the first test and the scores on the retest is used to estimate the reliability of the test. The tool was strongly reliable in which $R=94.6$.

\subsection{Pilot study}

Before starting data collection, pilot study was conducted using the developed questionnaire on 10 adults with hypertension. The pilot study was carried out to test the applicability and clarity of the constructed questionnaire and detect any obstacles or problems that might arise during the actual collection of data. Also, it estimated the time needed to fill the sheet with every adult with hypertension. Based on the result of the pilot study, the necessary modifications and clarifications of some question were done. The pilot sample was excluded from the total sample of the study to assure the stability of the result.

\subsection{Data collection \& procedure}

The data were collected in eight months ( 4 months for pretest data collection and intervention application and 4 months for posttest collection) the time of data collection starts from first of July 2014 to the end of February 2015.

At the beginning of the study, the adults with hypertension were divided randomly into two groups according to their residence (75 adults as study group from Abu-Mashhour village and 75 adults as control group from El-Shahid Fekry village). Adults with hypertension who agreed to be interviewed and accepted to participate in the study were included into the research.

Each subject was interviewed individually through home visit. The interview included the following 3 visits as the following:

First visit: The researcher introduced herself and explained the purpose of the study and magnitude of the problem to each adult with hypertension. Then, the researcher distributed and filled a copy of the pre-test questionnaire to all subjects with hypertension to assess their knowledge about hypertension, lifestyle modification and treatment compliance. The educated adults with hypertension filled the tool by themselves and the researcher filled the tool of uneducated adults. The filling of the interviewing questionnaire from each subject took about 25-30 minutes according to the subject's response. During the first visit, the researcher measured the blood pressure, and then anthropometric measurements of weight and height were taken and recorded to estimate BMI. It is calculated by dividing weight in kilogram by squared height in meters. BMI = weight $(\mathrm{kg}) / \mathrm{height}\left(\mathrm{m}^{2}\right)$.

After the measurements were taken, the researcher explained 1 st session of intervention using PowerPoint presentation on lab top system. It included general knowledge about hypertension as definition of blood pressure, hypertension, types of hypertension, classification of hypertension in adults, risk factors, signs and symptoms, diagnosis, and complication. 
This session took about 20-30 minutes. The first visit took about 1 hour.

Lifestyle modification educational session: The aim of the lifestyle modification educational session was to correct wrong knowledge and increase the awareness of the subjects about hypertension and encourage them to adopt appropriate behaviors to improve and control their blood pressure. Lifestyle modification program was developed by the researcher based on review of current literature. It was written in a simple Arabic language and supplemented by photos and illustrations to help the patient understanding the content. The developed educational intervention was explained to the study group of adults with hypertension at home. The researcher works as a guide for learning about hypertension management and provide the intervention in two sessions which was explained by the researcher through two home visits.

Second visit: In the second visit, second session was carried out in the same week, the researcher explained this session using booklet and PowerPoint presentation on lab top system. This session include explanation of the management of hypertension such as non-pharmacological treatment as nutrition, weight reduction, physical activity, smoking cessation, and stress management, and pharmacological management. Also, the researcher explained nutrients that can reduce hypertension, therapeutic nutrition for diabetes and hypertension, nutrition for diabetes, hypertension and renal failure in addition to nutrition for hypertension and high cholesterol and how to prevent high blood pressure. This session took about 30-45 minutes, and then a copy of the educational intervention booklet was given to each subject in the study group to attract his/her attention, motivate his/her, help for reviewing, and support teaching at home.

Third visit: Evaluation was applied by comparing knowledge, practice and behavior change for lifestyle modification before and after the intervention. This was done through reusing of the same tool after three months to perform posttest for both study and control groups to assess their retention of knowledge and assessing the effectiveness of application of pander's health promotion model on the management of hypertension. Blood pressure and anthropometric measurements also were taken. A copy of the educational intervention booklet was given to the control group included in the study. This visit took about 30-40 minutes.

\subsection{Statistical analysis}

Upon completion of data collection, the collected data were organized, tabulated and statistically analyzed using SPSS software (Statistical Product for services solution, version 16, SPSS Inc. Chicago, IL, USA). For quantitative data, the range, mean and standard deviation were calculated. For qualitative data, comparison between two groups and more was done using Chi-square test. For comparison between means of two groups, parametric analysis ( $t$-test) and nonparametric analysis ( $\mathrm{Z}$ value of Mann-Whitney $\mathrm{U}$ test) were used. For comparison between means of two related groups (pre \& post data) of parametric data, paired $t$-test was used. For comparison between means of two related groups' pre $\&$ post data) of non-parametric data, $\mathrm{Z}$ value of Wilcoxon Signed Ranks Test was used. For comparison between more than two means of non-parametric data, Kruskal-Wallis value was calculated. For comparison between percent of change testing of proportion was done ( $\mathrm{Z}$ test). Correlation between variables was evaluated using Pearson's correlation coefficient $(r)$. Significance was adopted at $p<.05$ for interpretation of results (Dawson \& Trapp, 2001).

\subsection{Limitations of the study}

- Tool of questionnaire was too long and thus makes many subjects bored to fill the questionnaire and refused to fill posttest questionnaire.

- It is difficult to obtain data about hypertension at Menoufia Governorate because there is no statistical record about hypertension cases.

\section{RESUltS}

Table 1 presented demographic data of the studied adults with hypertension (study and control groups). It illustrated that the highest percentages of hypertension were among age group between $50-60$ years $(44.7 \%)$, female $(69.3 \%)$, and illiterate $(34.7 \%)$. Also it showed that married adults had hypertension more than other marital status. Regarding occupation, it showed that housewives have hypertension higher than other occupations. Regarding monthly income, adults with enough monthly income showed the highest percentage of hypertension $(71.3 \%)$, and more than three quarter of hypertension $(78.0 \%)$ was among adults with family size 4-7 persons.

Table 2 presented distribution of medical data of the studied sample (study and control groups). It illustrated that more than half of the sample (58.0\%) diagnosed with hypertension since 1-6 years. Approximately three quarters of studied groups $(74.7 \%)$ diagnosed with hypertension by medical checkup. More than half of the adults complained from other diseases and diabetes mellitus is the most common disease among them. Regarding complication, it showed that the highest percentage of the sample had no complications related to hypertension $(84.0 \%)$ but retinopathy is the most common disease among those who had complications related to hypertension. 
Table 1. Distribution of demographic data of the studied adults with hypertension (study and control groups) $(\mathrm{n}=150)$

\begin{tabular}{|c|c|c|c|c|c|c|}
\hline \multirow{3}{*}{ Demographic data } & \multicolumn{6}{|c|}{ The study sample $(\mathrm{n}=150)$} \\
\hline & \multicolumn{2}{|c|}{ Study group $(n=75)$} & \multicolumn{2}{|c|}{ Control group $(n=75)$} & \multicolumn{2}{|c|}{ Total $(n=150)$} \\
\hline & $\mathbf{n}$ & $\%$ & $\mathbf{n}$ & $\%$ & $\mathbf{n}$ & $\%$ \\
\hline \multicolumn{7}{|l|}{ Age (years) } \\
\hline $18-$ & 1 & 1.3 & 2 & 2.7 & 3 & 2.0 \\
\hline $30-$ & 10 & 13.3 & 7 & 9.3 & 17 & 11.3 \\
\hline $40-$ & 32 & 42.7 & 24 & 32.0 & 56 & 37.3 \\
\hline $50-$ & 30 & 40.0 & 37 & 49.3 & 67 & 44.7 \\
\hline $60-64$ & 2 & 2.7 & 5 & 6.7 & 7 & 4.7 \\
\hline \multicolumn{7}{|l|}{ Sex } \\
\hline Males & 22 & 29.3 & 24 & 32.0 & 46 & 30.7 \\
\hline Females & 53 & 70.7 & 51 & 68.0 & 104 & 69.3 \\
\hline \multicolumn{7}{|l|}{ Educational level } \\
\hline Illiterate & 18 & 24.0 & 34 & 45.3 & 52 & 34.7 \\
\hline Basic & 19 & 25.3 & 22 & 29.3 & 41 & 27.3 \\
\hline Moderate education & 26 & 34.7 & 13 & 17.3 & 39 & 26.0 \\
\hline Highly educated & 12 & 16.0 & 6 & 8.0 & 18 & 12.0 \\
\hline \multicolumn{7}{|l|}{ Marital status } \\
\hline Single & 3 & 4.0 & 3 & 4.0 & 6 & 4.0 \\
\hline Married & 59 & 78.7 & 47 & 62.7 & 106 & 70.7 \\
\hline Divorced & 3 & 4.0 & 2 & 2.7 & 5 & 3.3 \\
\hline Widowed & 10 & 13.3 & 23 & 30.7 & 33 & 22.0 \\
\hline \multicolumn{7}{|l|}{ Occupation } \\
\hline House wife & 34 & 45.3 & 42 & 56.0 & 76 & 50.7 \\
\hline Employee & 31 & 41.3 & 23 & 30.7 & 54 & 36.0 \\
\hline Worker & 8 & 10.7 & 5 & 6.7 & 13 & 8.7 \\
\hline Farmer & 1 & 1.3 & 1 & 1.3 & 2 & 1.3 \\
\hline Retired & 1 & 1.3 & 4 & 5.3 & 5 & 3.3 \\
\hline \multicolumn{7}{|l|}{ Monthly income } \\
\hline Not enough & 12 & 16.0 & 17 & 22.7 & 29 & 19.3 \\
\hline Enough (for basic needs only) & 56 & 74.7 & 51 & 68.0 & 107 & 71.3 \\
\hline Enough \& save & 7 & 9.3 & 7 & 9.3 & 14 & 9.3 \\
\hline \multicolumn{7}{|l|}{ Family size (persons) } \\
\hline$<4$ & 9 & 12.0 & 10 & 13.3 & 19 & 12.7 \\
\hline $4-7$ & 61 & 81.3 & 56 & 74.7 & 117 & 78.0 \\
\hline$>7$ & 5 & 6.7 & 9 & 12.0 & 14 & 9.3 \\
\hline
\end{tabular}

Table 3 presented distribution of family medical history of the studied adults with hypertension (study and control groups). It illustrated that nearly one third of the sample (32.0\%) had family history of hypertension and $60 \%$ of the sample had smokers in their family.

Figure 1 showed that there was statistical significant improvement among the study group than that of the control group at the post test knowledge about hypertension $(p<.05)$.

Figure 2 showed that there was statistical significant improvement among the study group than the control group at the mean percent of improvement of total Hill-bone blood pressure medication compliance scale $(p<.05)$.

Table 4 presented total mean scores of behavior outcome (health promoting behavior) among the studied adults with hypertension (study and control groups) pre and posttest. It showed that there was statistical significant improvement among the study group than the control group at the post test of total mean scores of behavior outcome (health promoting behavior) $(p<.05)$. The highest mean score was in the posttest of nutrition dimension followed by medication adherence, stress management and physical activity but smoking had no statistical significant improvement. 
Table 2. Distribution of medical data of the studied adults with hypertension

\begin{tabular}{|c|c|c|c|c|c|c|}
\hline \multirow{3}{*}{ Medical data } & \multicolumn{6}{|c|}{ The study sample $(n=150)$} \\
\hline & \multicolumn{2}{|c|}{ Study group $(n=75)$} & \multicolumn{2}{|c|}{ Control group $(\mathrm{n}=75)$} & \multicolumn{2}{|c|}{ Total $(n=150)$} \\
\hline & $\mathbf{n}$ & $\%$ & $\mathbf{n}$ & $\%$ & $\mathbf{n}$ & $\%$ \\
\hline \multicolumn{7}{|c|}{ Duration of diagnosis of hypertension (years) } \\
\hline$<1$ & 5 & 6.7 & 6 & 8.0 & 11 & 7.3 \\
\hline $1-6$ & 48 & 64.0 & 39 & 52.0 & 87 & 58.0 \\
\hline $6-10$ & 8 & 10.7 & 10 & 13.3 & 18 & 12.0 \\
\hline$>10$ & 14 & 18.7 & 20 & 26.7 & 34 & 22.7 \\
\hline \multicolumn{7}{|c|}{ Diagnosis of hypertension } \\
\hline By chance & 15 & 20.0 & 23 & 30.7 & 38 & 25.3 \\
\hline By medical check up & 60 & 80.0 & 52 & 69.3 & 112 & 74.7 \\
\hline \multicolumn{7}{|l|}{ Complain from diseases } \\
\hline Yes & 43 & 57.3 & 45 & 60.0 & 88 & 58.7 \\
\hline No & 32 & 42.7 & 30 & 40.0 & 62 & 41.3 \\
\hline \multicolumn{7}{|l|}{ Diseases as } \\
\hline Diabetes mellitus & 26 & 60.5 & 24 & 53.3 & 50 & 56.8 \\
\hline Heart disease & 2 & 4.7 & 3 & 6.7 & 5 & 5.7 \\
\hline Liver disease & 3 & 7.0 & 2 & 4.4 & 5 & 5.7 \\
\hline Hypercholesterolemia & 9 & 20.9 & 10 & 22.2 & 19 & 21.6 \\
\hline Diabetes \& liver dis. & 0 & 0 & 2 & 4.4 & 2 & 2.3 \\
\hline All previous diseases & 3 & 7.0 & 4 & 8.9 & 7 & 8.0 \\
\hline \multicolumn{7}{|c|}{ Complications related to the disease } \\
\hline Yes & 9 & 12.0 & 15 & 20.0 & 24 & 16.0 \\
\hline No & 66 & 88.0 & 60 & 80.0 & 126 & 84.0 \\
\hline \multicolumn{7}{|l|}{ Complication (n = 24) } \\
\hline Stroke & 0 & 0 & 2 & 13.3 & 2 & 8.3 \\
\hline Myocardial infarction & 1 & 11.1 & 3 & 20.0 & 4 & 16.7 \\
\hline Renal failure & 0 & 0 & 1 & 6.7 & 1 & 4.2 \\
\hline Retinopathy & 8 & 88.9 & 7 & 46.7 & 15 & 62.5 \\
\hline Others & 0 & 0 & 2 & 13.3 & 2 & 8.3 \\
\hline
\end{tabular}

Table 3. Distribution of family medical history among the studied adults with hypertension

\begin{tabular}{|c|c|c|c|c|c|c|}
\hline \multirow{3}{*}{ Family medical history } & \multicolumn{6}{|c|}{ The study sample $(n=150)$} \\
\hline & \multicolumn{2}{|c|}{ Study group $(n=75)$} & \multicolumn{2}{|c|}{ Control group $(n=75)$} & \multicolumn{2}{|c|}{ Total $(n=150)$} \\
\hline & $\mathbf{n}$ & $\%$ & $\mathbf{n}$ & $\%$ & $\mathbf{n}$ & $\%$ \\
\hline \multicolumn{7}{|l|}{ Chronic diseases } \\
\hline Hypertension & 23 & 30.7 & 25 & 33.3 & 48 & 32.0 \\
\hline Diabetes mellitus & 9 & 12.0 & 8 & 10.7 & 17 & 11.3 \\
\hline Heart disease & 1 & 1.3 & 0 & 0 & 1 & 0.7 \\
\hline Obesity & 3 & 4.0 & 3 & 4.0 & 6 & 4.0 \\
\hline Diabetes \& hypertension & 10 & 13.3 & 13 & 17.3 & 23 & 15.3 \\
\hline \multicolumn{7}{|l|}{ Smokers in the family } \\
\hline Yes & 49 & 65.3 & 41 & 54.7 & 90 & 60.0 \\
\hline No & 26 & 34.7 & 34 & 45.3 & 60 & 40.0 \\
\hline
\end{tabular}




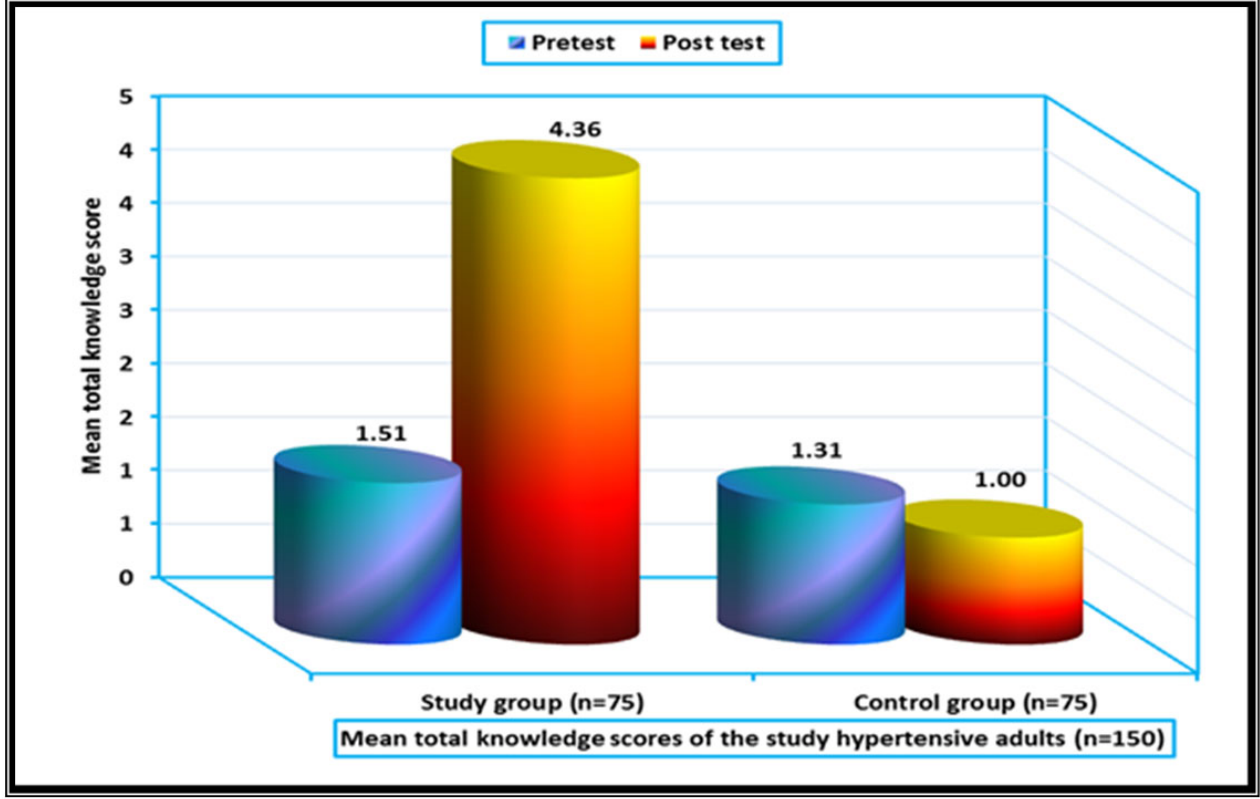

Figure 1. Mean scores of total knowledge of the studied hypertensive adults (study and control groups) about hypertension pre and posttest $(\mathrm{n}=15)$

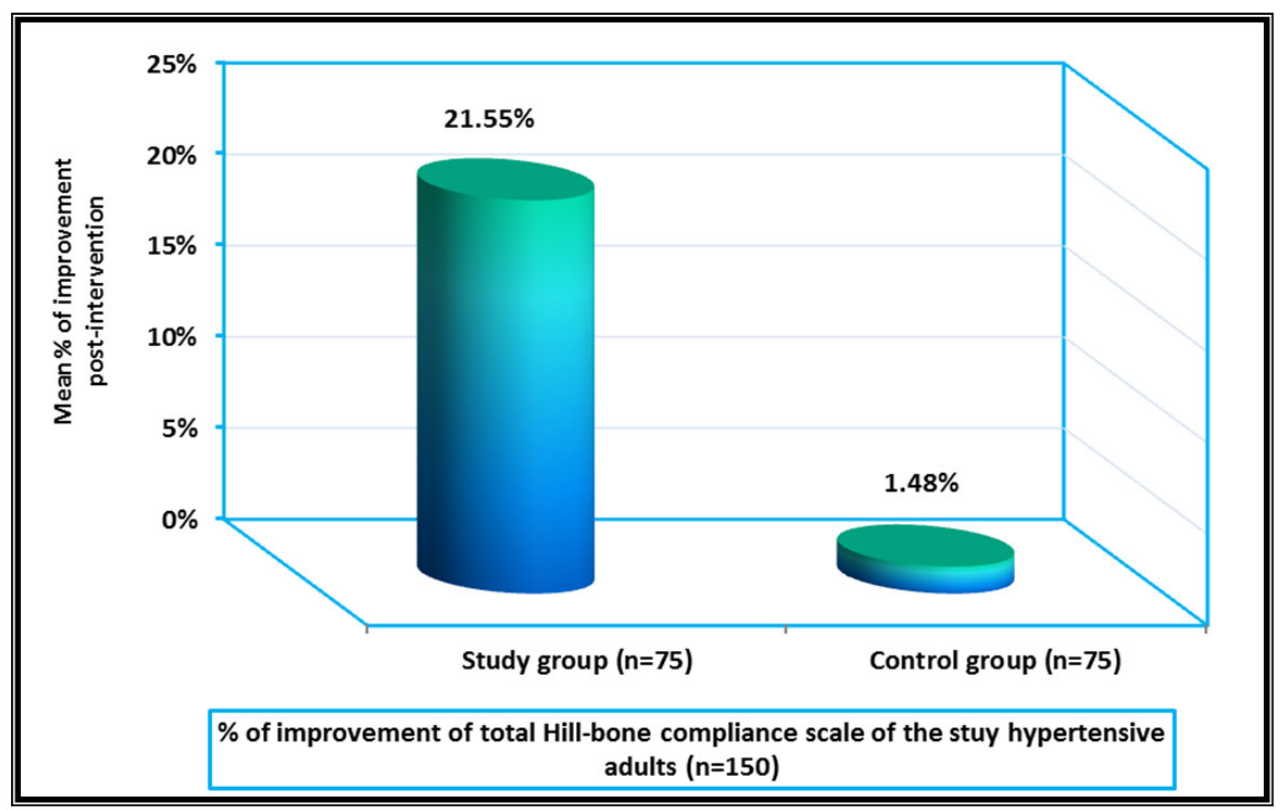

Figure 2. Mean percent of improvement of total Hill-bone blood pressure medication compliance scale among the studied adults with hypertension (study and control groups) post-intervention $(\mathrm{n}=150)$

Table 5 presented mean BMI and blood pressure of the study hypertensive adults (study and control groups) pre and posttest it showed that there was statistical significant improvement in systolic and diastolic blood pressure among the study group than the control group at the post test but there was no statistical significant difference regarding BMI.
Table 6 presented correlation between percent of improvement of systolic and diastolic blood pressure and components of the model among the studied adults post-intervention. It illustrated that there was statistical significant improvement in the systolic and diastolic blood pressure of the study group than the control group at the post test in relation to the components of Pender's health promotion model $p<.05$. 
Table 4. Total mean scores of behavior outcome (health promoting behavior) among the studied adults

\begin{tabular}{|c|c|c|c|c|}
\hline \multirow{3}{*}{ Behavior outcome (health promoting behavior) main items } & \multicolumn{2}{|c|}{ The study sample $(n=150)$} & \multirow{3}{*}{$t$-test } & \multirow{3}{*}{$p$} \\
\hline & Study group $(n=75)$ & Control group $(n=75)$ & & \\
\hline & Mean \pm SD & Mean \pm SD & & \\
\hline \multicolumn{5}{|l|}{ Nutritional adherence and weight reduction } \\
\hline Pretest & $28.15 \pm 4.08$ & $28.21 \pm 4.99$ & 0.090 & .929 \\
\hline Post test & $36.85 \pm 5.55$ & $28.24 \pm 5.01$ & 9.972 & $.0001^{*}$ \\
\hline \multicolumn{5}{|l|}{ Adherence to physical activity } \\
\hline Pretest & $6.48 \pm 1.54$ & $6.61 \pm 1.69$ & 0.504 & .615 \\
\hline Post test & $10.31 \pm 2.61$ & $6.61 \pm 1.69$ & 10.285 & $.0001^{*}$ \\
\hline \multicolumn{5}{|l|}{ Smoking cessation } \\
\hline Pretest & $2.15 \pm 1.17$ & $2.23 \pm 1.02$ & 0.446 & .656 \\
\hline Post test & $2.37 \pm 1.31$ & $2.23 \pm 1.02$ & 0.764 & .446 \\
\hline \multicolumn{5}{|l|}{ Stress management } \\
\hline Pretest & $16.96 \pm 2.23$ & $16.75 \pm 2.50$ & 0.551 & .582 \\
\hline Post test & $19.72 \pm 2.79$ & $16.76 \pm 2.51$ & 6.835 & .0001 \\
\hline \multicolumn{5}{|l|}{ Medication adherence } \\
\hline Pretest & $16.89 \pm 1.98$ & $16.52 \pm 2.34$ & 1.053 & .294 \\
\hline Post test & $21.81 \pm 2.84$ & $16.60 \pm 2.17$ & 12.618 & $.0001^{*}$ \\
\hline \multicolumn{5}{|l|}{ Total scores of behavior outcome (health promoting behavior) } \\
\hline Pretest & $70.63 \pm 6.79$ & $70.32 \pm 8.15$ & 0.250 & .803 \\
\hline Post test & $91.07 \pm 11.20$ & $70.44 \pm 8.01$ & 12.971 & $.0001^{*}$ \\
\hline
\end{tabular}

* Significant \& $(p<.05)$

Table 5. Mean body mass index (BMI), blood pressure of the study hypertensive adults (study and control groups) pre and posttest $(\mathrm{n}=150)$

\begin{tabular}{|c|c|c|c|c|c|c|c|c|c|c|}
\hline \multirow{4}{*}{ Variables } & \multicolumn{10}{|c|}{ The study hypertensive adults $(\mathrm{n}=\mathbf{1 5 0})$} \\
\hline & \multicolumn{4}{|c|}{ Study group $(n=75)$} & \multirow{3}{*}{$\begin{array}{l}\chi^{2} \\
p\end{array}$} & \multicolumn{4}{|c|}{ Control group $(n=75)$} & \multirow{3}{*}{$\begin{array}{l}\chi^{2} \\
p\end{array}$} \\
\hline & \multicolumn{2}{|c|}{ Pretest } & \multicolumn{2}{|c|}{ Post test } & & \multicolumn{2}{|c|}{ Pretest } & \multicolumn{2}{|c|}{ Post test } & \\
\hline & $\mathbf{n}$ & $\%$ & $\mathbf{n}$ & $\%$ & & $\mathbf{n}$ & $\%$ & $\mathbf{n}$ & $\%$ & \\
\hline \multicolumn{11}{|l|}{ BMI } \\
\hline Underweight $(<18.5)$ & 0 & 0 & 0 & 0 & \multirow{7}{*}{$\begin{array}{l}1.151 \\
.886\end{array}$} & 0 & 0 & 0 & 0 & \multirow{7}{*}{$\begin{array}{l}0.652 \\
.957\end{array}$} \\
\hline Normal $(18.5-<25)$ & 8 & 10.7 & 9 & 12.0 & & 6 & 8.0 & 6 & 8.0 & \\
\hline Overweight $(25-<30)$ & 24 & 32.0 & 25 & 33.3 & & 27 & 36.0 & 27 & 36.0 & \\
\hline Obese & & & & & & & & & & \\
\hline Class I $(30-<35)$ & 20 & 26.7 & 18 & 24.0 & & 22 & 29.3 & 19 & 25.3 & \\
\hline Class II (35-40) & 15 & 20.0 & 18 & 24.0 & & 9 & 12.0 & 12 & 16.0 & \\
\hline Class III (>40) & 8 & 10.7 & 5 & 6.7 & & 11 & 14.7 & 11 & 14.7 & \\
\hline \multicolumn{10}{|l|}{ Systolic BP } & \multirow{8}{*}{$\begin{array}{l}1.412 \\
.221\end{array}$} \\
\hline Optimal $(<120)$ & 0 & 0 & 1 & 1.3 & \multirow{7}{*}{$\begin{array}{l}43.992 \\
.0001^{*}\end{array}$} & 0 & 0 & 0 & 0 & \\
\hline Normal $(120-<130)$ & 0 & 0 & 4 & 5.3 & & 0 & 0 & 0 & 0 & \\
\hline $\begin{array}{l}\text { Pre-hypertension } \\
(130-<140)\end{array}$ & 0 & 0 & 13 & 17.3 & & 0 & 0 & 3 & 4.0 & \\
\hline Hypertension & & & & & & & & & & \\
\hline Stage I $(140-<160)$ & 17 & 22.7 & 26 & 34.7 & & 16 & 21.3 & 19 & 25.3 & \\
\hline Stage II $(160-<180)$ & 26 & 34.7 & 28 & 37.3 & & 29 & 38.7 & 30 & 40.0 & \\
\hline Stage III ( $\geq 180)$ & 32 & 42.7 & 3 & 4.0 & & 30 & 40.0 & 23 & 30.7 & \\
\hline \multicolumn{11}{|l|}{ Diastolic BP } \\
\hline Optimal $(<80)$ & 0 & 0 & 1 & 1.3 & \multirow{6}{*}{$\begin{array}{l}28.243 \\
.0001^{*}\end{array}$} & 0 & 0 & 0 & 0 & \multirow{6}{*}{$\begin{array}{l}0.393 \\
.335\end{array}$} \\
\hline Normal $(80-<85)$ & 0 & 0 & 10 & 13.3 & & 0 & 0 & 3 & 4.0 & \\
\hline $\begin{array}{l}\text { Pre-hypertension } \\
(85-<90) \\
\text { Hypertension }\end{array}$ & 0 & 0 & 0 & 0 & & 0 & 0 & 0 & 0 & \\
\hline Stage I $(90-<100)$ & 16 & 21.3 & 31 & 41.3 & & 12 & 16.0 & 14 & 18.7 & \\
\hline Stage II $(100-<110)$ & 32 & 42.7 & 32 & 42.7 & & 39 & 52.0 & 35 & 46.7 & \\
\hline Stage III $(\geq 110)$ & 27 & 36.0 & 1 & 1.3 & & 24 & 32.0 & 23 & 30.7 & \\
\hline
\end{tabular}


Table 6. Correlation between percent of improvement of systolic and diastolic blood pressure and components of model among the studied sample

\begin{tabular}{|c|c|c|c|c|}
\hline \multirow{3}{*}{ \% of improvement of components of model } & \multicolumn{4}{|c|}{$\%$ of improvement of blood pressure among the study sample $(n=150)$} \\
\hline & \multicolumn{2}{|c|}{ Systolic BP $(n=150)$} & \multicolumn{2}{|c|}{ Diastolic BP $(n=150)$} \\
\hline & $r$ & $p$ & $r$ & $p$ \\
\hline Knowledge about hypertension & 0.310 & $.0001^{*}$ & 0.391 & $.0001^{*}$ \\
\hline Total Hill-bone blood pressure medication compliance scale & 0.421 & $.0001^{*}$ & 0.062 & .451 \\
\hline \multicolumn{5}{|l|}{ Behavior-specific cognition and affects } \\
\hline Perceived benefits from compliance to hypertension management & 0.137 & .095 & 0.062 & .451 \\
\hline Barriers that prevent from compliance to hypertension management & -0.521 & $.0001^{*}$ & -0.425 & $.0001^{*}$ \\
\hline Perceived self-efficacy to modify lifestyle to manage hypertension & 0.435 & $.0001 *$ & 0.301 & $.0001^{*}$ \\
\hline Interpersonal influences & 0.119 & .18 & 0.070 & .393 \\
\hline Situational influences & 0.237 & $.004 *$ & 0.106 & .133 \\
\hline \multicolumn{5}{|l|}{ Behavior outcome (health promoting behavior) } \\
\hline Nutritional adherence and weight reduction & 0.592 & $.0001^{*}$ & 0.452 & $.0001^{*}$ \\
\hline Adherence to physical activity & 0.633 & $.0001^{*}$ & 0.468 & $.0001^{*}$ \\
\hline Smoking cessation & 0.330 & $.0001^{*}$ & 0.186 & $.023 *$ \\
\hline Stress management & 0.435 & $.0001^{*}$ & 0.439 & $.0001^{*}$ \\
\hline Medication adherence & 0.434 & $.0001^{*}$ & 0.428 & $.0001^{*}$ \\
\hline
\end{tabular}

\section{Discussion}

Hypertension is one of the most important cardiovascular risk factor but its control is still a challenge all around the world. Control of blood pressure can reduce cardiovascular morbidity and mortality, so the compliance to antihypertensive drugs and life style modification play an important role for the control of hypertension. ${ }^{[15]}$ Education and information at all levels play a key role in promoting health and maintain normal blood pressure. Evidence to date indicates that well documented information and education can indeed change knowledge and behavior and can thereby improve blood pressure. ${ }^{[23]}$

Concerning personal factors, the present study revealed that high prevalence of hypertension was among housewives, adults with enough monthly income and those with family size 4-7 persons. This finding is congruent with Nurhan, Dilek \& Demir (2012) ${ }^{[24]}$ who reported that hypertension was higher in subjects who had no occupation, higher in adults with low monthly income. Also, they reported that a linear association was observed between family size and the prevalence of hypertension. This similarity might be due to that Housewives tend to be obese which can be a risk factor for hypertension also increase family size can lead to increase psychosocial pressures which increase liability to hypertension. Also, low socioeconomic status can lead to ignorance of buying medication or engaging in lifestyle modification for treatment of hypertension.

Regarding personal and family medical history of adults with hypertension, the present study revealed that approximately

Published by Sciedu Press three quarter of adults with hypertension diagnosed with hypertension by medical checkup. More than half of the adults with hypertension complained from diseases other than hypertension and diabetes mellitus (DM) followed by hypercholesterolemia is the most common disease among them. Regarding family history, it illustrated that nearly one third of subjects had family history of hypertension followed by DM and HTN together. Regarding smoking, more than half of the adults with hypertension had smokers in their family. This finding is supported by Nkosi $(2010)^{[25]}$ who reported that other risk factor for hypertension is high blood cholesterol and DM were discovered in the study sample. Also, obesity, hypertension, diabetes and stroke were the common risk factors from their mother's side. Also, this finding is supported by Nurhan, Dilek \& Demir (2012) ${ }^{[24]}$ they reported that a significant association between hypertension and family history of hypertension. Also, there were subjects who had both DM and HTN. Regarding smoking; he reported that there was a significant association between HTN and passive smoking. The prevalence of HTN was higher in nonsmokers than the smokers. These findings might be due to that adults with hypertension didn't go to the physician until signs and symptoms occur. Also, any adult with a family history of hypertension, several genes may interact with each other and the environment to cause the blood pressure to elevate over time. In addition, negative smoking is more serious than positive smoking.

In relation to mean score of total knowledge of the studied sample about hypertension, the present study revealed 
that there was statistical significant improvement among the study group than the control group at the post test knowledge about hypertension. This finding is congruent with Abd Elattif (2008) ${ }^{[26]}$ who studied dietary management for hypertensive patients and its effects on nutritional status and blood pressure level, Egypt. She revealed that there was a significant difference before and after conducting the intervention which indicated an improvement of the patient mean knowledge scores after intervention. Also, this finding is supported by Verna \& Bourne $(2013)^{[27]}$ who studied hypertensive patients: knowledge, self-care management practices and challenges in Jamaican urban hospitals, India. They reported that a significant statistical difference in the knowledge levels of respondents on hypertension. This similarity might be due to that the study group received an educational sessions which work as a guide to increase their knowledge about hypertension than of the control group.

Concerning mean scores of total Hill-bone blood pressure medication compliance scale of the studied sample (study and control groups) pre and posttest. The present study illustrated that more than three quarters of the study group have good drug compliance to antihypertensive drug at posttest than the control group. Also, it showed that there was statistical significant improvement among the study group than the control group at the posttest of mean score of total Hill-bone blood pressure medication compliance scale. This finding is supported by Angelina (2012) ${ }^{[21]}$ who studied factors affecting treatment compliance among hypertension patients in three districts hospitals- Dar Es Salaam, Tanzania. He reported that more than half of hypertensive patients were having good drug compliance. This finding is not supported by a study that was done by Nasir, Muhammad, Syed \& Waqas $(2008)^{[28]}$ who studied compliance to antihypertensive drugs, Salt restriction, Exercise and Control of systemic hypertension in hypertensive patients at Abbottabad, Pakistan. They reported that nearly half of hypertensive patients were complaints to antihypertensive drugs and more than half of them were not compliant to the drugs. The discrimination might be due to that different sample characteristics and size also; non-compliance was affected by forgetfulness of the adults with hypertension, deliberately missing doses, due to side effects, increased number of tablets, not properly counseled, and due to cost issues.

Regarding mean scores of main items of behavior outcome (health promoting behavior) among the studied sample (study and control groups) pre and posttest. The present study showed that that there was statistical significant improvement among the study group than the control group at the post test of health promoting behavior. The highest mean score was in the posttest of nutrition dimension followed by medication adherence, stress management and physical activity but smoking had no statistically significant improvement. This finding is congruent with Al-Wehedy, Hassan, \& Abd El-Hameed (2014) ${ }^{[29]}$ who studied effect of lifestyle intervention program on controlling hypertension among older adults, Egypt. They reported that the mean scores for total and all dimensions of lifestyle patterns were increased (improved) significantly in the study group at 3 months post sessions and the improvement maintained at 6 month evaluation Also, This finding is supported by Thuyen \& Earmporn $(2013)^{[30]}$ who reported that the statistical significant improvement in the overall health promoting behavior of sample were at a moderate level. But this study is different from the present study in the degree of improvement in all dimensions except smoking and alcohol consumption were found at very good level which meant the subjects avoided smoking and drinking alcohol at much. The discrimination might be due to the period of intervention is long which help in the improvement in smoking or difference in culture.

In relation to the changes in blood pressure of the studied adults with hypertension (study and control groups) pre and posttest. The present study showed that there was statistical significance improvement among the study group than the control group at the post test of systolic and diastolic pressure. This finding is supported by Al-Wehedy, Hassan, \& Abd El-Hameed (2014) ${ }^{[29]}$ who reported that systolic and diastolic blood pressure measurements decreased significantly among the study group than the control group post 3 and 6 months of session implementation. This finding might be due to lifestyle patterns correlated significantly with control of systolic and diastolic blood pressure which means that high adoption of healthy lifestyle associated with better blood pressure control.

Concerning correlation between percent of improvement of systolic and diastolic blood pressure and components of the model among the studied adults with hypertension (study and control groups) pre and posttest. The present study showed that there was statistical significant improvement in the systolic and diastolic blood pressure of the study group than the control group at the post test of in relation to the components of Pender's health promotion model. This finding is congruent with Kamaran, Azadbakht, Sharifirad, Mahaki, and Mohebi (2015) ${ }^{[31]}$ who studied the relationship between blood pressure and the structures of Pender's health promotion model in rural hypertensive patients, Ardebil city. They reported that significant correlation between self-efficacy, perceived benefits, situational influences, affects related to behavior and commitment to action structures with SBP and showed a positive significant correlation between perceived barriers and SBP. Furthermore, age and body mass 
and knowledge had direct significant relation with SBP. The structures of health promotion model have in overall the prediction power of SBP changes. This finding could be due to lifestyle educational session has an important role in improvement of hypertensive knowledge, behavior and practices.

\section{Conclusions}

In the light of the present study findings, it can be concluded that Application of Pender's Health Promotion Model was effective in management of hypertension. Also, nursing educational intervention was successful in improving knowledge, lifestyle behaviors and blood pressure measurement among adults in the study group than the control group.

\section{RECOMMENDATIONS}

- Health education programs and educational guidebook to increase awareness of adults about risk factors of hypertension and the disease process are essential to empower and motivate them adopt healthy lifestyle and adhere to medication to manage the disease and prevent complications.

- A comprehensive treatment plan is recommended to be provided to all clients with hypertension attending the family health center to help them and their caregiver understand and follow accurately the required therapeutic regimen.

- Follow up visits either to the clinic or through home visits are important to evaluate the progress of patient's condition and motivate them adhere with preventive measures through promoting healthy lifestyle to prevent complications.

- The use of mass media as television, magazines and internet could be added to the educational intervention program for hypertension management. If welldesigned, these Medias could potentially add a lively, modern, colorful and attractive channel for the messages to reach the families.

\section{CONFlicts OF INTEREST Disclosure}

The authors declare that there is no conflict of interest.

\section{REFERENCES}

[1] Ogedegbe PM, Whelton M, Reynolds K, et al. Global burden of hypertension: analysis of worldwide data. Lancet. 2013; 365: 217-223.

[2] World Health Organization. Egypt hypertension. Cairo: [Accessed April 25, 2011]. Available from: http://www.emro.who.int/n cd/pdf/who_em_ncd_044_e_en.pdf

[3] National Health and Nutrition Examination Survey. Prevalence of hypertension in United States. J Nutr. 2012; 134: 3398-3399.

[4] Centers for Disease Control and Prevention National Institutes of Health. Healthy People 2010. Heart Disease and Stroke. 2011. Available from: http://www.healthypeople.gov/Document/HTML/ Volume1/12Heart.htm

[5] Tailakh A, Evangelista LS, Mentes JC, et al. Hypertension prevalence, awareness, and control in Arab countries: a systematic review. Nurs Health Sci. 2014 Mar; 16(1): 126-30. PMid:24118852 http://dx.doi.org/10.1111/nhs. 12060

[6] WHO \& ARE-Ministry of Health \& Population. Egypt National STEPwise Survey of Non Communicable Diseases Risk Factors. 2012.

[7] Cunha JP. High blood pressure (hypertension). 2011. Available from: http://www.medicinenet.com/high_blood_pressur e/article.htm

[8] Lopez MN. Lifestyle modification counseling for hypertensive patients: Results from the National Health and Nutrition: A Textbook of Cardiovascular Medicine. 8th ed. Philadelphia, Pa: Saunders Elsevier; 2009.

[9] Achananuparp A. A comparative study of two modes of treatment for hypertension. Fam Pract. 2008; 9(3): 304-310.

[10] Lemone R, Burke T. Comprehensive individualized nonpharmacological treatment program for hypertension in physician-nurse clinics: two year follow-up. J Hum Hypertens. 2011; 7: 585-591.
[11] Ibrahim MM, Rizk H, Appel WA, et al. Hypertension prevalence, awareness, treatment, and control in Egypt. Results from the Egyptian National Hypertension Project (NHP). NHP Investigative Team Hypertension. 2011; 26(6): 886-890. http://dx.doi .org/10.11 61/01.HYP. 26.6.886

[12] Pereira M, Lunet N, Azevedo A, et al. Differences in prevalence, awareness, treatment and control of hypertension between developing and developed countries. J Hypertens. 2009; 27(5): 963-975. http://dx.doi.org/10.1097/HJH. Ob013e3283282f65

[13] Taymoori P, Lubans D, Berry T. Evaluation of the health promotion model to predict physical activity in iranian adolescent boys. Health Education \& Behavior. 2010; 37(84): 84-96. PMid:20130301 http://dx.doi.org/10.1177/1090198109356407

[14] Oliviera AS, Chen RS, McCarthy BD, et al. Hypertension Knowledge, Awareness, and Attitudes in a Hypertensive Population. 2009 Available from: http://www.ncbi.nlm.nih.gov/pmc/article s

[15] Miller NH, Berra K, Long J. Awareness, understanding, and treatment of previously diagnosed hypertension in baby boomers and seniors: a survey conducted by harris interactive on behalf of the preventive cardiovascular Nurses association. J Clin Hypertens. 2010; 12(5): 328-334. PMid:20546373 http://dx.doi.org/10.1111 /j.1751-7176.2010.00267.x

[16] Purananoon P, Narapong W, Kreggultron T. Health promoting behaviors Health behavior of the elderly in rural Kaeng Khoi District, Saraburi Province. Journal of Gerontology and Geriatric Medicine. 2010; 7(3): 2-9.

[17] World Health Organization. Regional Office for the Eastern Mediterranean. Report on the consultation on establishing regional guidelines on osteoporosis. Cairo: [Accessed January 25, 2012]. Avail- 
able from: http://www.emro. who.int/ncd/pdf/who_em_ncd_ 044_e_en.pdf

[18] Pender NJ, Murdaugh CL, Parsons MA. Health Promotion in Nursing Practice. Pearson education Inc.Upper Saddle River, New Jersey; 2002. $60 \mathrm{p}$

[19] Janet OK. Prevention and management of hypertension: A study on knowledge and attitudes of women of childbearing age. Central Ostrobothnia. University of applied sciences. Koforidua. 2011.

[20] Kim MT, Hill MN, Bone LR, et al. Development and testing of the hill-bone compliance to high blood pressure therapy scale. Progress in Cardiovascular Nursing. 2000; 15(3): 90-96. http: //dx.doi.org/10.1111/j.1751-7117.2000.tb00211.x

[21] Angelina AJ. Factors affecting treatment compliance among hypertension patients in three districts hospitals- Dar Es Salaam. Master thesis, Muhimbili University of Health and Allied Sciences. 2012.

[22] Glenn EH. Personal Factors, Perceptions, Influences and Their Relationship with Adherence Behaviors in Patients with Diabetes. Nursing Dissertations. Paper 16. Georgia State University. 2010. Available from: http://scholarworks.gsu.edu/nursing_diss

[23] World Health Organization. Hypertension assessment, prevention and control: a guide for programme managers (document WHO/NHD/01.3). World Health Organization, Geneva; 2001; 1-150.

[24] Nurhan D, Dilek T, Demir D. Hypertension prevalence and risk factors among adult population in Afyonkarahisar region: a crosssectional research. Turkey. Hypertens. 2012; 21: 1983-92.
[25] Nkosi M. Knowledge related to nutrition and hypertension management practices of adults in Ga-Rankuwa day clinics. South Africa. Curationis. 2010; 27: 63-69.

[26] Abd Elattif OM. Dietary management for hypertensive patients and its effects on nutritional status and blood pressure level, Doctorate Thesis. Faculty of Nursing. Menoufia University. 2008.

[27] Verna E, Bourne A. Hypertensive patients: knowledge, self-care management practices and challenges in Jamaican urban hospitals. $\mathrm{J}$ Behav Health. 2013; 2(3): 259-268.

[28] Nasir A, Muhammad A, Syed HS, et al. Compliance to antihypertensive drugs, Salt restriction, Exercise and Control of systemic hypertension in hypertensive patients at Abbottabad. Ayub Med. 2008; 20(2): 66-68.

[29] Al-Wehedy A, Hassan S, Abd El-Hameed D. Effect of lifestyle intervention program on controlling hypertension among older adults, Faculty of Nursing, Mansoura University, Egypt. Journal of Education and Practice. 2014; 5(5).

[30] Thuyen HN, Earmporn RN. Factors Affecting Health-Related Behaviors in Adults with Hypertension in Khanh Hoa Province, Vietnam. 2013. Available from: http://www.answers.com/topic/heal th-related-behavior

[31] Kamaran A, Azadbakht L, Sharifirad H, et al. The relationship between blood pressure and the structures of Pender's health promotion model in rural hypertensive patients. J Edu List Promot. 2015. 